\title{
Low dose dobutamine stress echocardiography predicts the improvement of left ventricular systolic function in dilated cardiomyopathy
}

\author{
H Kitaoka, J Takata, T Yabe, N Hitomi, T Furuno, Y L Doi
}

\begin{abstract}
Objective-To determine whether dobutamine stress echocardiography can predict the improvement of left ventricular systolic function in patients with dilated cardiomyopathy (DCM).

Methods-Myocardial contractile reserve, as assessed by dobutamine stress echocardiography, was determined in 18 patients with DCM (mean (SD) age 53 (13) years, left ventricular ejection fraction (LVEF) 28 (10)\%) and compared with changes in LVEF during a follow up period of 15 (8) months. The LVEF and regional left ventricular wall motion score $(0$, normal to 4, dyskinesis) of 12 segments in short axis and four chamber views were analysed before and after dobutamine infusion $(5-20 \mu \mathrm{g} / \mathrm{kg} / \mathrm{min})$.
\end{abstract}

Results-During a follow up period of 15 (8) months, a significant improvement in LVEF ( $>20 \%$ ) was found in seven patients but not in the remaining 11. Baseline haemodynamic findings were similar in both groups. Patients with an improvement in follow up LVEF showed a greater change in wall motion score from baseline during dobutamine infusion than patients with no improvement (at rest, $1.7(0.4) v$ $1.9(0.2), \mathrm{NS}$; dobutamine $10 \mu \mathrm{g} / \mathrm{kg} / \mathrm{min}$, $0.6(0.4) v 1.2(0.4), \mathrm{p}<0.05)$. The percentage change in LVEF during dobutamine infusion was also significantly greater in patients who showed improvement than in those who did not. The change in LVEF during the follow up period (follow up LVEF/baseline LVEF) correlated well with the change in LVEF during dobutamine stress (LVEF at rest/ LVEF at dobutamine $10 \mu \mathrm{g} / \mathrm{kg} / \mathrm{min}$; $r=0.74, \mathrm{p}<0.001)$.

Conclusions-Changes in left ventricular systolic performance during low dose dobutamine stress echocardiography are a useful marker to predict the outcome of left ventricular systolic function in patients with DCM.

(Heart 1999;81:523-527)

Keywords: dilated cardiomyopathy; dobutamine stress echocardiography; contractile reserve

Idiopathic dilated cardiomyopathy (DCM) has a poor prognosis, although treatment with vasodilators, angiotensin converting enzyme (ACE) inhibitors, and $\beta$ blockers has been shown to improve the prognosis in patients with heart failure. ${ }^{1-3}$ On the other hand, it is reported that some patients with DCM experience an improvement in left ventricular systolic function. ${ }^{4-7}$ Although in such patients prediction of improvement is important in considering eligibility for heart transplantation, it has been reported that there are no significant differences in the clinical characteristics determined at initial examination-except in relation to myocardial fibrosis observed in endomyocardial biopsies and alcohol consumption-between patients showing improvement and those who do not. ${ }^{8-10}$

Dobutamine stress echocardiography has been widely used in assessing the myocardial viability and prognosis in patients with ischaemic left ventricular dysfunction. ${ }^{11}{ }^{12}$ However, its value in patients with non-ischaemic left ventricular dysfunction is not clear. Our purpose in this study was to clarify whether dobutamine stress echocardiography can predict the improvement of left ventricular systolic function in patients with DCM.

\section{Methods}

SUBJECTS

We studied 18 patients with DCM. A careful history was taken from all the patients, and they were given a physical examination, blood test, chest $x$ ray, standard electrocardiography, exercise stress test, dipyridamole stress, ${ }^{201} \mathrm{Tl}$ scintigraphy, and cardiac catheterisation, including coronary angiography and biplane left ventriculography. Patients with acute myocarditis, significant coronary artery stenosis, valvar disease, or a left ventricular end diastolic volume below $85 \mathrm{ml} / \mathrm{m}^{2}$ were excluded. All patients were initially treated with ACE inhibitors, diuretics, and digitalis. Seven patients were also treated with $\beta$ blockers.

DOBUTAMINE STRESS ECHOCARDIOGRAPHY

After baseline electrocardiography and echocardiography had been recorded, dobutamine was infused intravenously, beginning at 5 $\mu \mathrm{g} / \mathrm{kg} / \mathrm{min}$ and increasing to 10 and 20 $\mu \mathrm{g} / \mathrm{kg} / \mathrm{min}$ at five minute intervals, with continuous electrocardiography and blood pressure monitoring.

The left ventricular end diastolic dimensions and end systolic dimensions were measured in the parasternal longitudinal position. The left ventricular ejection fraction (LVEF) was calculated according to a previously reported method. ${ }^{13}$ The left ventricle was divided into 12 segments (six in the short axis view and six in the four chamber view). The wall motion score 
Table 1 Baseline, echocardiographic, and haemodynamic characteristics

\begin{tabular}{|c|c|c|c|}
\hline & $\begin{array}{l}\text { Group } A \\
(n=7)\end{array}$ & $\begin{array}{l}\text { Group B } \\
(n=11)\end{array}$ & $p$ Value \\
\hline \multicolumn{4}{|l|}{ Clinical findings } \\
\hline Age (years) & 49 (13) & $55(15)$ & NS \\
\hline Range & $(23$ to 60$)$ & (23 to 70$)$ & \\
\hline Male/female & $5 / 2$ & $10 / 1$ & \\
\hline NYHA class (II/III) & $6 / 1$ & $8 / 3$ & NS \\
\hline$\beta$ Blocker use & 4 & 3 & NS \\
\hline Alcohol intake (> $100 \mathrm{~g} /$ day) & 3 & 4 & NS \\
\hline \multicolumn{4}{|l|}{ Echocardiographic findings } \\
\hline $\operatorname{LVEDD}(\mathrm{mm})$ & $59(9)$ & $65(7)$ & NS \\
\hline LVESD (mm) & $52(9)$ & $56(8)$ & NS \\
\hline \multicolumn{4}{|l|}{ Haemodynamic findings } \\
\hline LVEF (\%) & $35(8)$ & $33(9)$ & NS \\
\hline LVEDVI $\left(\mathrm{ml} / \mathrm{m}^{2}\right)$ & $154(48)$ & $157(49)$ & NS \\
\hline $\operatorname{LVESVI}\left(\mathrm{ml} / \mathrm{m}^{2}\right)$ & $95(30)$ & $105(40)$ & NS \\
\hline LVEDP (mm Hg) & $9(3)$ & $16(10)$ & NS \\
\hline $\mathrm{PCW}(\mathrm{mm} \mathrm{Hg})$ & $8(2)$ & $12(9)$ & NS \\
\hline PA mean $(\mathrm{mm} \mathrm{Hg})$ & $20(5)$ & $22(9)$ & NS \\
\hline RVEDP (mm Hg) & $7(2)$ & $9(5)$ & NS \\
\hline RA mean (mm Hg) & $5(2)$ & $6(4)$ & NS \\
\hline Cardiac index $\left(1 / \mathrm{min} / \mathrm{m}^{2}\right)$ & $2.7(0.7)$ & $2.2(0.5)$ & NS \\
\hline
\end{tabular}

Values are $\mathrm{n}$ or mean (SD).

LVEDD, left ventricular end diastolic dimension; LVEDVI, left ventricular end diastolic volume index; LVEF, left ventricular ejection fraction; LVEDP, left ventricular end diastolic pressure; LVESD, left ventricular end systolic dimension; LVESVI, left ventricular end systolic volume index; NYHA, New York Heart Association; PA, pulmonary artery; PCW, pulmonary capillary wedge pressure; RA, right atrium; RVEDP, right ventricular end diastolic pressure.

( 0 , normal; 1 , mild hypokinesis; 2 , severe hypokinesis; 3, akinesis; 4, dyskinesis) was obtained for each segment at rest and at a dobutamine dose of 5,10 , and $20 \mu \mathrm{g} / \mathrm{kg} / \mathrm{min}$. The wall motion score index (WMSI), defined as the sum of the wall motion scores divided by the number of segments, was also analysed.

THALLIUM-201 MYOCARDIAL SCINTIGRAPHY

${ }^{201} \mathrm{Tl}$ SPECT was performed in 17 patients. The left ventricular myocardium was divided into 13 segments using basal and mid-short axis slices and an apical slice. ${ }^{201} \mathrm{Tl}$ uptake was then scored in each segment using a grading scale (3, normal; 2 , mildly reduced; 1 , moderately reduced; 0 , severely reduced).

CARDIOPULMONARY EXERCISE TEST

Symptom limited cardiopulmonary exercise testing was performed in 15 patients on an upright bicycle ergometer. Exercise workload

Table 2 Cardiovascular response to dobutamine

\begin{tabular}{|c|c|c|c|}
\hline & Group $A$ & Group B & $p$ Value \\
\hline \multicolumn{4}{|l|}{ Rest } \\
\hline HR (beats/min) & $88(15)$ & $72(15)$ & NS \\
\hline Systolic BP (mm Hg) & $120(16)$ & $122(16)$ & NS \\
\hline $\operatorname{LVEF}(\%)$ & $27(9)$ & $29(11)$ & NS \\
\hline \multicolumn{4}{|l|}{$5 \mu \mathrm{g} / \mathrm{kg} / \mathrm{min}^{\star}$} \\
\hline $\mathrm{HR}$ & $92(13)$ & $76(15)$ & NS \\
\hline Systolic BP & $138(25)$ & $131(17)$ & NS \\
\hline LVEF & $43(10)$ & $39(12)$ & NS \\
\hline \multicolumn{4}{|l|}{$10 \mu \mathrm{g} / \mathrm{kg} / \mathrm{min}^{*}$} \\
\hline HR & $106(18)$ & $84(16)$ & $<0.05$ \\
\hline Systolic BP & $147(29)$ & $142(21)$ & NS \\
\hline LVEF & $52(13)$ & $41(15)$ & NS \\
\hline \multicolumn{4}{|l|}{$20 \mu \mathrm{g} / \mathrm{kg} / \mathrm{min}^{\star}$} \\
\hline $\mathrm{HR}$ & $130(32)$ & $109(22)$ & NS \\
\hline Systolic BP & $142(30)$ & $147(22)$ & NS \\
\hline LVEF & $51(9)$ & $44(16)$ & NS \\
\hline
\end{tabular}

Values are mean (SD)

^Dobutamine dose.

$\mathrm{BP}$, blood pressure; HR, heart rate; LVEF, left ventricular ejection fraction.

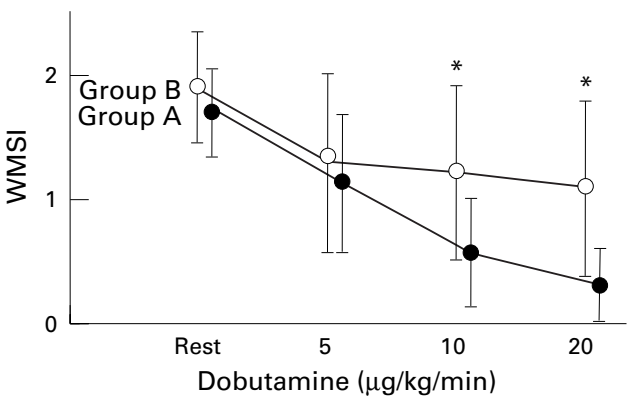

Figure 1 Serial change in mean wall motion score index (WMSI) during dobutamine stress echocardiography. A greater improvement of wall motion was observed in group $A$ than in group $B .{ }^{*} p<0.05$.

was increased by the ramp incremental protocol of $15 \mathrm{~W} / \mathrm{min}$ after pedalling against zero resistance for one minute. All patients stopped exercise on presentation of dyspnoea or leg fatigue - that is, above 18 on the Borg scale. The electrocardiographic findings and blood pressure measured by sphygmomanometer were recorded at rest, at every minute during exercise, and for five minutes after exercise.

The expired gas was measured on a breath by breath basis during the test with a respiromonitor AE280 (Minato Medical Electronics, Osaka, Japan) connected to a personal computer equipped with analysing software.

FOLLOW UP

The mean (SD) follow up period was 15 (8) months. Follow up echocardiography and clinical outcome was obtained in all patients. A significant improvement of LVEF (greater than $20 \%$ ) was found in seven patients (group A); however, no such improvement occurred in the remaining 11 patients (group B).

STATISTICAL ANALYSIS

Results are expressed as mean (SD). Unpaired $t$ and $\chi^{2}$ tests were used for comparison of the two groups. Linear regression analysis was used to evaluate the correlation between the response of the left ventricle to dobutamine and

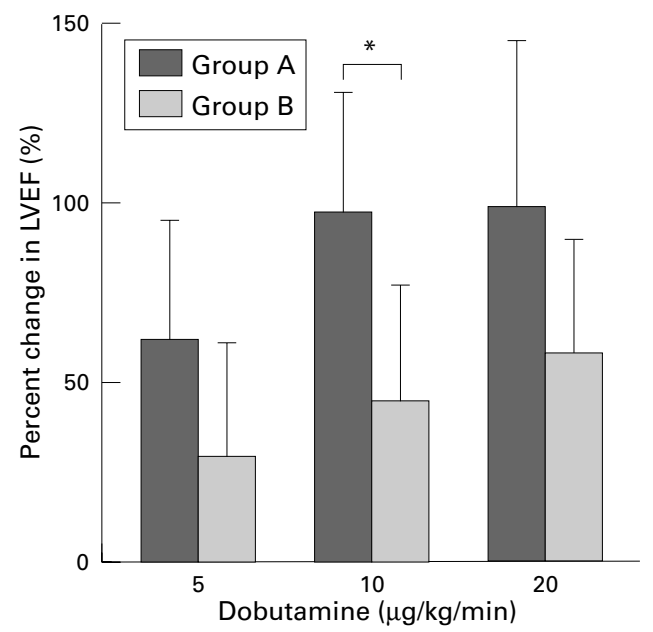

Figure 2 Change in LVEF (LVEF during dobutamine infusion - LVEF at rest/LVEF at rest). This was significantly greater in group $A$ at the dobutamine infusion dose of $10 \mathrm{mg} / \mathrm{kg} / \mathrm{min} .{ }^{\star} p<0.05$. 
Group A

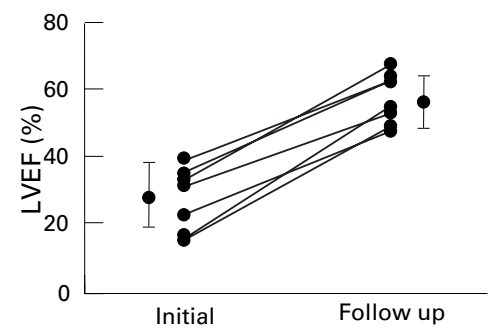

Group B

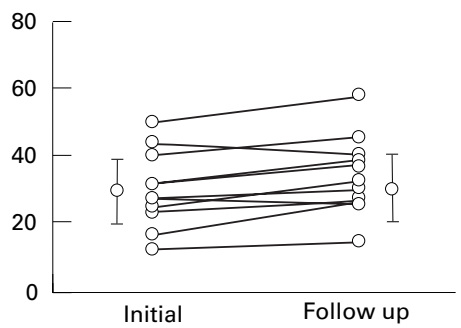

Figure 3 LVEF at the initial examination and at the last follow up in the two groups.

the improvement of left ventricular systolic function during the follow up period. A p value of $<0.05$ was considered statistically significant.

\section{Results}

BASELINE CHARACTERISTICS AND CLINICAL OUTCOME

Baseline, echocardiographic, and haemodynamic characteristics are shown in table 1 . There were no significant differences in baseline and haemodynamic characteristics between the two groups, although group A tended to have somewhat lower baseline left ventricular end diastolic pressure and pulmonary capillary wedge pressure, and higher cardiac index compared with group B. The mean ${ }^{201} \mathrm{Tl}$ uptake score in 13 segments was similar between the two groups (group A, $2.1(0.5) v$ group B, 2.3 (0.3), NS). A large perfusion defect exceeding one segment was found in one patient in group A and in two patients in group B. Peak oxygen consumption in cardiopulmonary exercise testing was also not significantly different between the two groups (group A, $18.5(5.3) \mathrm{ml} / \mathrm{min} / \mathrm{kg} v$ group $\mathrm{B}, 18.2$ (3.6) $\mathrm{ml} / \mathrm{min} / \mathrm{kg}$ ), although heart rate at rest and at low level exercise in group A was higher than in group B (rest, 88.7 (9.6) $v 78.9$ (11.3) beats/min; $45 \mathrm{~W}, 110.5$ (10.9) $v 100.7(8.4)$ beats/min; 60 W, 116.5 (6.5) v 108.3 (9.6) beats/min, NS). One patient in group A and three patients in group B experienced congestive heart failure during the follow up period.

DOBUTAMINE STRESS ECHOCARDIOGRAPHY Cardiovascular response to dobutamine infusion No patients complained of chest pain or dyspnoea, neither were ventricular tachycardia
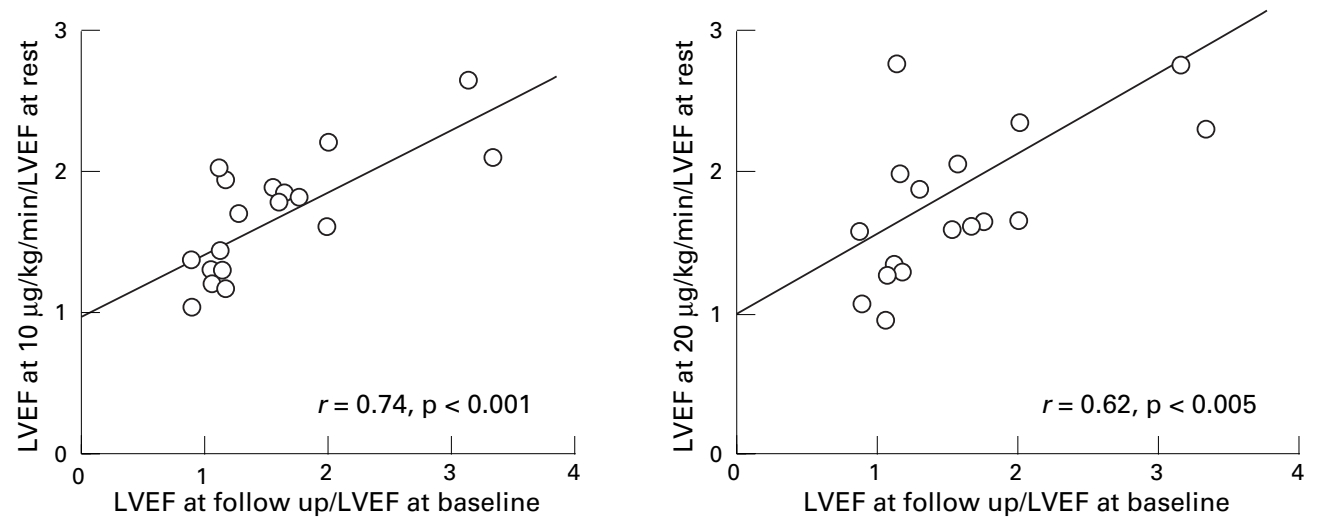

Figure 4 Correlation between the response of LVEF to dobutamine and the improvement of LVEF during the follow up period. A good correlation was shown at dobutamine infusion doses of both $10 \mu \mathrm{g} / \mathrm{kg} / \mathrm{min}$ and $20 \mu \mathrm{g} / \mathrm{kg} / \mathrm{min}$. and hypotension observed in any patient. Heart rate and blood pressure responses during dobutamine infusion are shown in table 2. There were no significant differences between the two groups except that heart rate at the dobutamine infusion rate of $10 \mu \mathrm{g} / \mathrm{kg} / \mathrm{min}$ was faster in group A.

\section{Wall motion score index}

WMSI values are shown in fig 1 . The WMSI at rest was $1.7(0.4)$ in group A and $1.9(0.5)$ in group B (NS). After dobutamine stress, the WMSI in group A became significantly smaller than in group B both at $10 \mu \mathrm{g} / \mathrm{kg} / \mathrm{min}(0.6(0.4)$ v $1.2(0.7), \mathrm{p}<0.05)$ and at $20 \mu \mathrm{g} / \mathrm{kg} / \mathrm{min}$ (0.30 (0.3) v $1.1(0.7), \mathrm{p}<0.05)$, although it gradually improved in both groups (fig 1). Thus the change in WMSI in group A was greater than in group B. With a cut off value of WMSI set at 1.0 at $10 \mu \mathrm{g} / \mathrm{kg} / \mathrm{min}$, sensitivity and specificity in predicting future improvement of LVEF were $85 \%$ and $81 \%$, respectively. Positive predictive value was $75 \%$.

\section{Left ventricular ejection fraction}

Changes in LVEF are shown in table 2 and fig 2. The LVEF tended to increase during dobutamine infusion in both groups. A greater mean increase in LVEF in group $A$ than in group B was not statistically significant (table 2 ). Figure 2 shows the percent change in LVEF (LVEF at each dobutamine dose minus LVEF at rest divided by LVEF at rest). The percentage change in LVEF in group A was significantly greater than in group B at the dobutamine infusion rate of $10 \mu \mathrm{g} / \mathrm{kg} / \mathrm{min}$ (98 (33) $\%$ v $45(33) \%, \mathrm{p}<0.005)$.

\section{RESPONSE OF LVEF TO DOBUTAMINE AND} FOLLOW UP IMPROVEMENT

The LVEF values at the initial examination and nition in this study, a significant improvement in LVEF was observed in group A (27 (9)\% $\rightarrow$ $56(8) \%, \quad p<0.0001)$, whereas minimal change was seen in group B $(29(11) \% \rightarrow 34$ (11) $\%$, p < 0.005)

We examined the correlation between the response of LVEF to dobutamine and follow up improvement (LVEF at follow up/LVEF at baseline). As shown in fig 4 , the response of at the last follow up are shown in fig 3. By defi- 
LVEF both at 10 and $20 \mu \mathrm{g} / \mathrm{kg} / \mathrm{min}$ was well correlated with follow up LVEF improvement.

\section{Discussion}

In this study, a significant improvement of left ventricular systolic function was seen in seven $(39 \%)$ of 18 patients with DCM, and this improvement correlated well with the response of left ventricular function during the dobutamine stress echocardiography at baseline.

NATURAL HISTORY OF DCM

Idiopathic DCM-characterised by dilated ventricles and decreased systolic function-has usually been regarded as having a poor prognosis. In early reports, survival was 70 $75 \%$ at one year and $50 \%$ at five years. ${ }^{414}$ However, in recent reports the prognosis has been better, with a five year survival rate of $65-80 \%{ }^{15}{ }^{16}$ Earlier detection of the disease as well as newer treatments with ACE inhibitors and $\beta$ blockers may be related to this improvement in prognosis.

On the other hand, a marked improvement in left ventricular systolic function has been reported in $20-45 \%$ of patients with DCM. ${ }^{5} 8$ In this study, an improvement in left ventricular function was observed in 39\% of the patients. In line with previous findings, this relatively high percentage of patients with improvement may well be related to our earlier use of ACE inhibitors and $\beta$ blockers. It is also possible that there were some patients with myocarditis in our study, since changes in ventricular size and function are common in these patients; however, we did our best to exclude patients with a possible history of myocarditis. Nonetheless, to be able to predict such improvements non-invasively is of clinical importance in patients with non-ischaemic left ventricular dysfunction, particularly in relation to indications for heart transplantation.

\section{FACTORS INFLUENCING THE IMPROVEMENT OF}

LEFT VENTRICULAR FUNCTION

Haemodynamic variables determined at initial examination have not been associated with improvement in left ventricular systolic function..$^{58}$ The extent of myocardial fibrosis in endomyocardial biopsies and the alcohol intake have been reported to be factors influencing improvement in left ventricular systolic function. ${ }^{8}{ }^{16}$ In our study, there was no statistical difference between the initial haemodynamic findings and the alcohol intake between patients with and without improvement, although patients with improvement had slightly lower baseline left ventricular end diastolic pressure and pulmonary capillary wedge pressure and a higher cardiac index than those without improvement, suggesting better cardiac function and reserve. Myocardial biopsies were not obtained. Thallium scintigraphy did not reveal any difference in uptake score or prevalence of large perfusion defects between patients with and without improvement. It is therefore important to find other means of predicting improvement in left ventricular systolic function non-invasively in patients with DCM.
DOBUTAMINE STRESS ECHOCARDIOGRAPHY Pharmacological stress echocardiography with dobutamine is recognised as useful in patients with myocardial infarction. It is reported that myocardial viability can be identified, using low dose dobutamine stress, as a functional improvement in regions with rest dyssynergy. The wall motion response during dobutamine infusion is useful in predicting of recovery of stunned myocardium and hibernating myocardium in patients with ischaemic heart disease. ${ }^{11} 12$

However, there are few reports concerning the significance of dobutamine stress echocardiography in patients with DCM. Vigna et al reported that the analysis of regional contraction by dobutamine stress echocardiography could distinguish between ischaemic and nonischaemic left ventricular dysfunction. ${ }^{17}$ However, to our knowledge, this is the first report on predicting the recovery of systolic function by dobutamine stress echocardiography in patients with DCM. The exact mechanism of this recovery is unclear. One explanation is the degree of downregulation of the myocardial $\beta$ adrenergic system, since this has been reported to be associated with progressive left ventricular deterioration. Patients with improvement show the better heart rate response to low dose dobutamine as well as to low level exercise, suggesting that contractile reserve related to $\beta$ adrenergic stimulation may be the predominant factor in the improvement in wall motion score. Doubois-Rande et al investigated the relation between the contractile responsiveness to intracoronary dobutamine infusion and the clinical outcome in patients with DCM, and reported that diminished $\beta$ adrenergic contractile reserve was predictive of the clinical outcome. ${ }^{18}$ There may also be "non-contractile but viable" myocardium in patients with non-ischaemic left ventricular dysfunction, and this may play a part in the recovery of systolic function.

STUDY LIMITATIONS

Limitations include the small number of patients studied and the retrospective nature of the study. Another limitation is the variation in drug treatment. In particular, patients showing improvement in LVEF were more likely to be receiving $\beta$ blockers, and it has been reported that $\beta$ blockers and ACE inhibitors improve LVEF in different ways. Finally, myocardial biopsies were not performed, although we excluded patients clinically suspected of having myocarditis or secondary myocardial disease.

\section{CLINICAL IMPLICATIONS}

Dobutamine stress echocardiography can safely be applied to patients with DCM and may predict the extent of recovery of left ventricular systolic function. The findings of this study may be useful in the decision making process before heart transplantation or left ventricular volume reduction (Batista operation). This study was presented in part at the 46th annual scientific
session of the American College of Cardiology, Anaheim, March session of the American College of Cardiology, Anaheim, March
1997. We thank Taishiro Chikamori MD, Hiromi Seo MD, Yoshihisa Matsumura MD, and Kazuhiko Sugimoto MD for their advice throughout the study. 
1 Cohn JN, Johnson G, Ziesche S, et al. A comparison of enalapril with hydralazine-isosorbide dinitrate in the treatment of chronic con

2 Waagstein F, Bristow MR, Swedberg K, et al. Beneficial effects of metoprolol in idiopathic dilated cardiomyopathy. Lancet 1993;342:1441-6.

3 Packer M, Colucci WS, Sackner-Bernstein J. Double-blind, placebo-controlled study of the effects of carvedilol in patients with moderate to severe heart failure: the PRECISE trial. Circulation 1996;94:2793-9.

4 Fuster V, Gersh BJ, Giuliani ER, et al. The natural history of idiopathic dilated cardiomyopathy. Am f Cardiol 1981;47: 525-31.

5 Francis GS, Johnson TH, Ziesche S, et al. Marked spontaneous improvement in ejection fraction in patients with congestive heart failure. Am ₹ Med 1990;89:303-7.

6 Steimle AE, Stevenson LW, Fonarow GC, et al. Prediction of improvement in recent onset cardiomyopathy after referof improvement in recent onset cardiomyopathy after refol

7 Cross AM, Steenbergen C, Higginbotham MB. Recovery of left ventricular function in acute nonischemic congestive left ventricular function in acute nonischem

8 Figula HR, Rahlf G, Nieger M, et al. Spontaneous hemodynamic improvement or stabilization and associated biopsy findings in patients with congestive cardiomyopathy. Circulation 1985;71:1095-104.

9 Yamada T, Fukunami M, Ohmori M, et al. Which subgroup of patients with dilated cardiomyopathy would benefit from $628-33$.
10 Regan JT. Alcoholic cardiomyopathy. Prog Cardiovasc Dis 1986;8:52-6.

11 Pierard LA, deLandsheere CM, Berthe C, et al Identification of viable myocardium by echocardiography during dobutamine infusion in patients with myocardial infarction after thrombolytic therapy: comparison with positron emission tomography. 7 Am Coll Cardiol 1990;5:1021-31.
Cigarroa CG, deFilippi CR, Brickner E, et al. Dobutamine Cigarroa CG, deFilippi CR, Brickner E, et al. Dobutamine
stress echocardiography identifies hibernating myocardium stress echocardiography identifies hibernating myocardium onary revascularization. Circulation 1993;88:430-6.

13 Pombo JF, Troy BL, Russell RO. Left ventricular volumes and ejection fraction by echocardiography. Circulation 1972;46:26-30

14 Ikram H, Williamson HG, Won M, et al. The course of idiopathic dilated cardiomyopathy in New Zealand. Br Heart $f$ 1987;57:521-7.

15 Sugrue DD, Rodeheffer RJ, Codd MB, et al. The clinical course of idiopathic dilated cardiomyopathy: a populationcourse of idiopathic dilated cardiomyopathy: a
based study. Ann Intern Med 1992;117:117-23.

16 Abelmann WH. Classification and natural history of primary myocardial disease. Prog Cardiovasc Dis 1984;27: 73-94.

17 Vigna C, Russo A, Rito VD, et al. Regional wall motion analysis by dobutamine stress echocardiography to distinguish between ischemic and nonischemic dilated cardiomyopathy. Am Heart f 1996;131:537-43.

18 Dubois-Rande JL, Merlet $\mathrm{P}$, Roudot $\mathrm{F}$, et al. $\beta$-Adrenergic contractile reserve as a predictor of clinical outcome in patients with idiopathic dilated cardiomyopathy. Am Heart f 1992;124:679-85. 